Check for updates

Cite this: Nanoscale Adv., 2019, 1, 1021

\section{Designing highly crystalline multifunctional multicolor-luminescence nanosystem for tracking breast cancer heterogeneity}

\author{
Avijit Pramanik, ${ }^{a}$ Salma Begum, ${ }^{a}$ Chris Rightsell, ${ }^{b}$ Kaelin Gates, ${ }^{a}$ Qinku Zhang, ${ }^{a}$ \\ Stacy Jones, ${ }^{a}$ Ye Gao, (D) a Vikram Ruppa-Kasani, (D) a Rimika Banerjee, ${ }^{a}$ \\ Jayanti Shukla, ${ }^{a}$ Ashley Ignatius, ${ }^{a}$ Dhiraj Sardar, ${ }^{\text {b }}$ Fengxiang. X. Han $^{\text {a }}$ \\ and Paresh Chandra Ray (D) *ab
}

Breast tumor heterogeneity was responsible for the death of 40000 women in 2017 in the USA. Triplenegative breast cancers (TNBCs) are very aggressive, and this is the only subgroup of breast cancers that still lacks effective therapeutics. As a result, the early-stage detection of TNBCs is vital and will have huge significance in clinical practice. Driven by this need, we here report the design of highly crystalline antibody-conjugated multifunctional multicolor-luminescence nanosystems derived from the naturally available popular tropical fruits mangoes and prunes, which have the ability to detect breast cancer heterogeneity via the selective separation and accurate identification of TNBC and HER-2(+) or ER/PR(+) breast cancer cells selectively and simultaneously. The detailed synthesis and characterization of the multifunctional multicolor nanosystems derived from tropical fruits have been reported. Experimental results show that by changing the fruits multicolor-luminescence carbon dots (LCDs) can be developed, which is mainly due to the formation of highly crystalline nanodots with different heavy metal dopants and is also due to the presence of different types of surface functional group. Experimental data that are presented show that the multifunctional multicolor nanoprobe can be used for the highly selective and simultaneous capture of targeted TNBC and HER-2(+) or ER(+) breast cancer cells, and the capture efficiency can be as high as $98 \%$. Reported data indicate that multicolor fluorescence imaging can be used for mapping heterogeneous breast cancer cells simultaneously and can distinguish targeted TNBC from non-targeted HER-2(+) or ER/PR(+) breast cancer. Our finding suggests the excellent potential of the design of multicolor nanosystems derived from natural fruits for detecting cancer heterogeneity in clinical practice.
Received 13th July 2018

Accepted 25th November 2018

DOI: $10.1039 / c 8 n a 00089 a$

rsc.li/nanoscale-advances
HER-2, currently there is no targeted therapy for TNBC in clinical practice, and as a result patients with TNBC suffer from very poor therapeutic outcomes. ${ }^{4-10}$ TNBC is well known to be a highly aggressive form of cancer, and as a result the standard techniques used in clinics such as mammograms, magnetic resonance imaging (MRI) and ultrasound usually detect TNBCs at later stages. ${ }^{\mathbf{1 - 1 5}}$ The above facts clearly indicate that mapping breast cancer heterogeneity is one of the highest priorities of current breast cancer research for improving the treatment of TNBC. Driven by this need, we here report a facile approach for the design of highly crystalline antibody-conjugated multifunctional multicolor-luminescence nanosystems derived from the naturally available popular tropical fruits mangoes and prunes, as shown in Schemes $1 \mathrm{~A}$ and $\mathrm{B}$, which have the ability to detect breast cancer heterogeneity via the selective separation and accurate identification of TNBC and HER-2(+) or ER/PR(+) breast cancer cells from a mixture.

Luminescent carbon dots (LCDs) are a new class of bioimaging nanomaterials, of which the surface contains multiple
${ }^{a}$ Department of Chemistry and Biochemistry, Jackson State
USA. E-mail: paresh.c.ray@jsums.edu; Fax: + 16019793674

${ }^{b}$ Department of Physics and Astronomy, University of Texas at San Antonio, San Antonio, Texas 78249, USA 
A

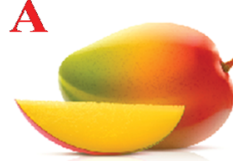

Freeze dried Mango

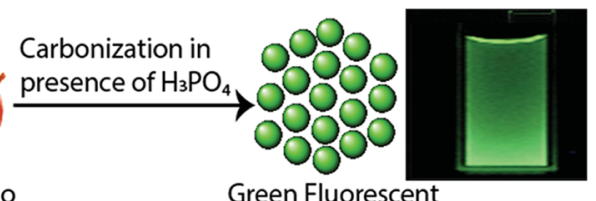

Green Fluorescent

Carbon dots

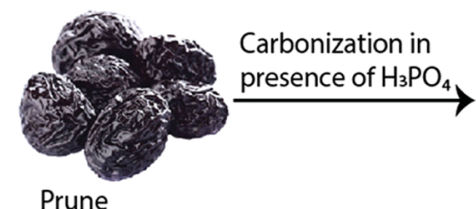

Prune

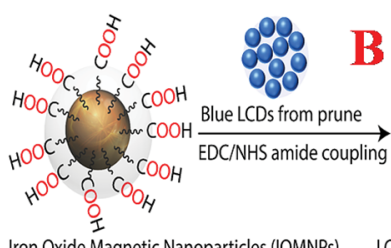

Iron Oxide Magnetic Nanoparticles (IOMNPs)

LCDs attached IOMNPs

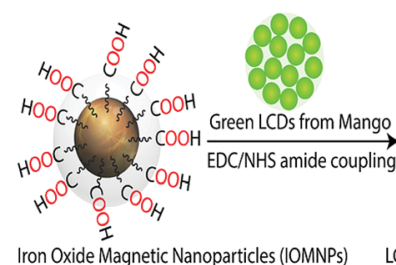

Iron Oxide Magnetic Nanoparticles (IOMNPS)

LCDs attached IOMNPS

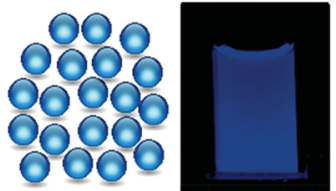

Bluish-white Fluorescent Carbon dots

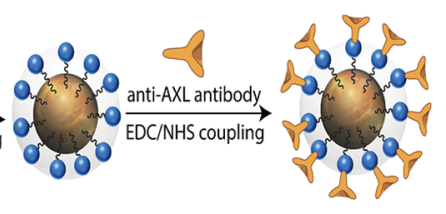

Antibody modified LCDs attached IOMNPs

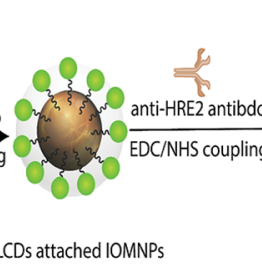

LCDs attached IOMNPS

Scheme 1 (A) Fruit-based synthetic route we used for the development of blue and green fluorescent carbon dots. (B) Synthetic procedure we used for the development of antibody-conjugated blue and green fluorescent magnetic LCDs.

oxygen-containing moieties. ${ }^{20-30}$ Because LCDs exhibit remarkably bright photoluminescence due to quantum confinement effects and also exhibit very high biocompatibility, photostability and aqueous solubility, ${ }^{30-40}$ LCDs can be highly promising candidates for applications in daily life. ${ }^{41-49}$ The photoluminescence wavelength of LCDs can be varied by varying their size, shape and surface states. ${ }^{20-30}$ Because the surface states of LCDs are critical to their wavelengthdependent photoemission properties, ${ }^{30-40}$ we report a green synthesis route for the development of blue- and green-colored LCDs by controlling the contents of nitrogen $(\mathrm{N})$, sulfur (S), phosphorus $(\mathrm{P})$ and other minerals using prune and mango fruits. $^{50,51}$ Prunes are dried fruits of the plum Prunus domestica L., which contain phytochemicals, sorbitol, volatile compounds and minerals such as phosphorus, boron, copper, manganese, potassium, iron and retinol. ${ }^{50}$ The mango, which has the scientific name Mangifera indica $\mathrm{L}$., contains more than 270 volatile compounds, including ethyl butanoate and 4hydroxy-2,5-dimethyl-3(2H)-furanone, numerous phytochemicals and minerals such as phosphorus, zinc, selenium, potassium and magnesium. ${ }^{51}$ By changing the fruits, we produced LCDs with different colors, which were mainly due to the presence of different surface functional groups, which

introduced new energy levels for electron transitions with comparable intensities. Similarly, with the change of fruits, doping with different heavy metals occurred, which also introduced new energy levels for electron transitions. For the selective separation and imaging of TNBC cells, we developed multifunctional magnetic-fluorescent LCDs by developing LCDs to which magnetic nanoparticles were attached. In our design, the magnetic properties of the multifunctional LCDs were used for the selective separation of each type of breast cancer cell, namely, HER-2(+), ER/PR(+) or TNBC. Furthermore, the multicolor-fluorescence LCDs were used to visualize different types of breast cancer cell for detection via multicolor fluorescence imaging to provide an accurate diagnosis.

\section{Results and discussion}

\section{Design of blue fluorescent LCDs from prunes}

Blue fluorescent LCDs were synthesized by the hydrothermal treatment of prunes using $\mathrm{H}_{3} \mathrm{PO}_{4}$.

The experimental details are described in the Experimental section. For this purpose, dried prunes were dissolved in water and $\mathrm{H}_{3} \mathrm{PO}_{4}$. After sonication for $5 \mathrm{~min}$, the solution was put in an autoclave and heated at $180^{\circ} \mathrm{C}$ for $2 \mathrm{~h}$. The product was then neutralized with $\mathrm{NaOH}$. Finally, the product was dialyzed against water for $72 \mathrm{~h}$ and then filtered. The blue fluorescent carbon dots were further purified by dialysis and then stored at $4{ }^{\circ} \mathrm{C}$. After the synthesis, we purified the particles using silica column chromatography. Finally, the prune-based LCDs were characterized by high-resolution tunneling electron microscopy (HR-TEM), energy-dispersive X-ray (EDX) spectroscopy, powder X-ray diffraction (XRD), X-ray photoelectron spectroscopy (XPS), infrared (IR) spectroscopy, fluorescence spectroscopy and dynamic light scattering (DLS) measurements, ${ }^{15-19,29,46,49}$ as reported in Fig. 1A-J. Fig. 1A shows a TEM image of freshly prepared LCDs from prunes, which indicates that the size of the prune-based LCDs was $8 \pm 2 \mathrm{~nm}$. Fig. 1B and Table 1 report the DLS data, which also indicate that the average size of freshly prepared LCDs from prunes was about $7 \pm 3 \mathrm{~nm}$, which matches the TEM data quite well. To understand and characterize the lattice structure, we also performed high-resolution TEM (HR-TEM) on freshly prepared LCDs from prunes. The HR-TEM image of a single particle of freshly prepared LCDs from prunes in the inset of Fig. 1A shows well-resolved lattice fringes with an interplanar spacing of $0.38 \mathrm{~nm}$, which are due to graphitic carbon. The observed spacing is slightly larger than that of bulk graphite, which is $0.334 \mathrm{~nm}$. This is due to the presence of functional groups and nitrogen, $\mathrm{Zn}, \mathrm{Mg}$ and other dopant atoms, which increased the basal plane spacing. Fig. 1C shows the XPS spectrum of freshly prepared blue luminescent CDs from prunes, which indicates the presence of carbon, $\mathrm{N}, \mathrm{O}$, $\mathrm{Zn}$ and $\mathrm{Mg}$ by the presence of peaks due to $\mathrm{C}_{1 \mathrm{~s}}(25.0 \%), \mathrm{O}_{1 \mathrm{~s}}$ (10\%), $\mathrm{N}_{1 \mathrm{~s}}(31 \%), \mathrm{Mg}_{1 \mathrm{~s}}(10 \%)$, and $\mathrm{Zn}_{2 \mathrm{p}}(15 \%)$. EDX elemental mapping of freshly prepared LCDs from prunes, as reported in Fig. 1E, indicates the presence of $\mathrm{N}, \mathrm{C}, \mathrm{O}, \mathrm{K}, \mathrm{Mg}, \mathrm{Zn}$, etc. The EDX elemental analysis data match the XPS analysis data very well. High-resolution XPS analysis indicates the presence of 

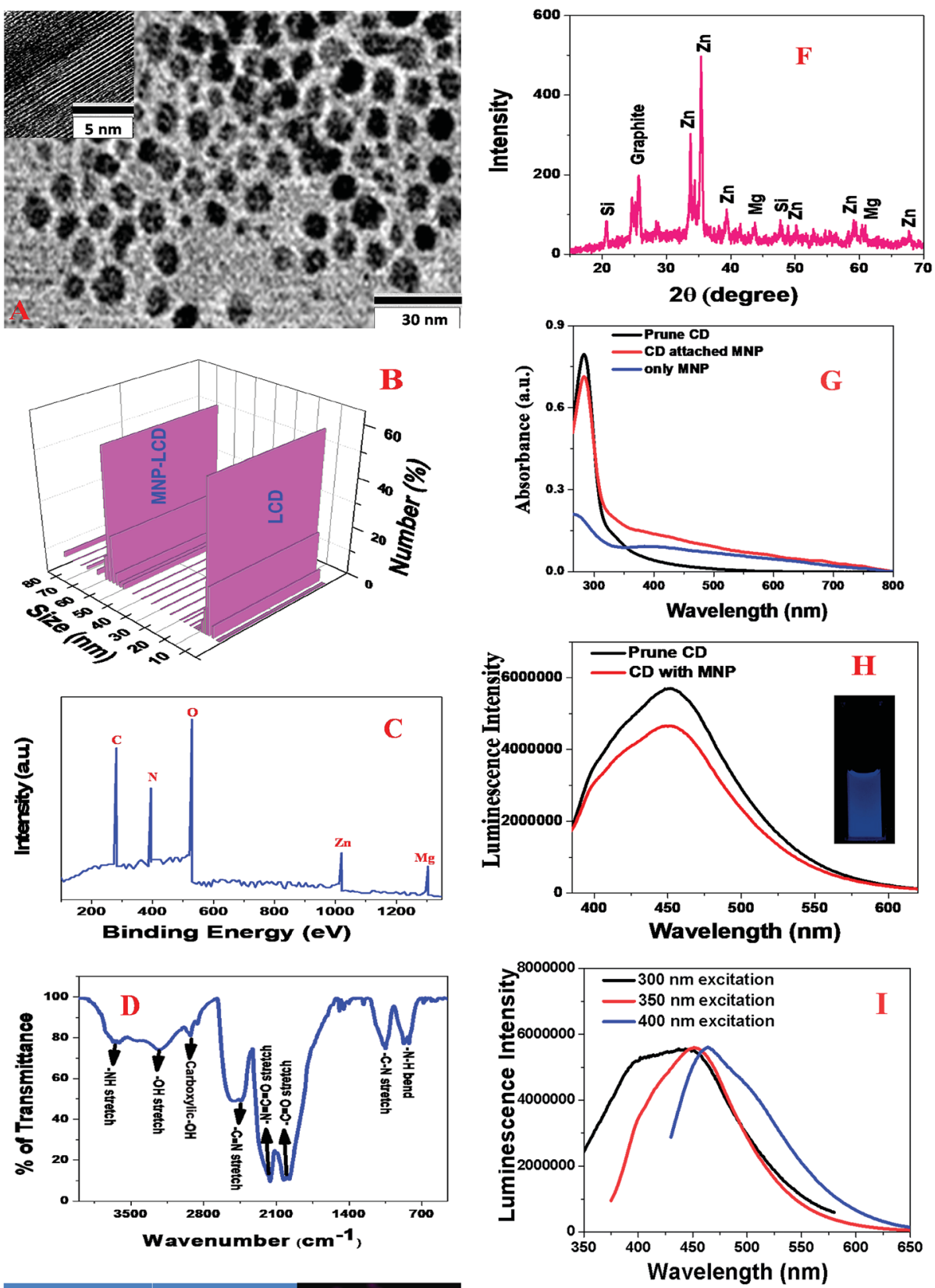

\begin{tabular}{|c|c|c|}
\hline Element & Mass $\%$ & $-8 * * 10$ \\
\hline $\mathrm{C}$ & 24 & \\
\hline $\mathbf{N}$ & 12 & \\
\hline O & 30 & 8 \\
\hline $\mathbf{Z n}$ & 15 & \\
\hline Mg & 9 & $35 \geq 0$ \\
\hline $\mathbf{S i}$ & 6 & \\
\hline $\mathbf{N a}$ & 2 & \\
\hline $\mathbf{S}$ & 2 & $\cos =8 \mathrm{Zn}$ \\
\hline
\end{tabular}

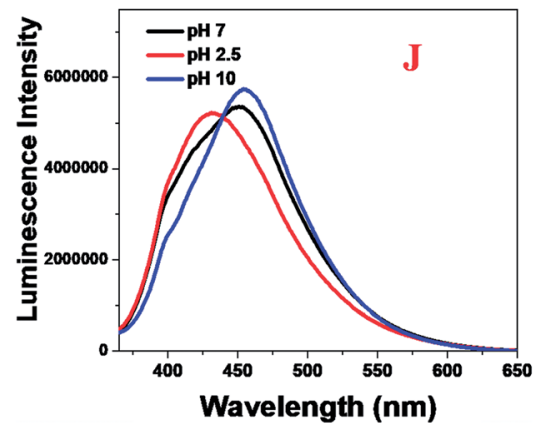

Fig. 1 (A) TEM image of freshly prepared blue luminescent CDs from prunes. Inset: HR-TEM image of a single particle showing well-resolved lattice fringes with an interplanar spacing of $0.38 \mathrm{~nm}$, which are due to graphitic carbon. (B) DLS data showing a histogram of the size distributions of the freshly prepared blue luminescent CDs (LCDs) from prunes and LCDs attached to magnetic nanoparticles. (C) XPS spectrum of freshly prepared blue luminescent CDs from prunes showing peaks due to carbon, N, O, Zn and Mg at 284.8, 398, 532.8, 1024, and 1303 eV, respectively. (D) FTIR spectrum of freshly prepared LCDs from prunes showing the presence of different types of surface functional group, such as $-\mathrm{NH}$, $-\mathrm{OH}$, $\mathrm{C}=\mathrm{O}, \mathrm{C}=\mathrm{N},-\mathrm{N}=\mathrm{C}=\mathrm{O}$, etc. (E) EDX elemental mapping of freshly prepared LCDs from prunes showing the presence of $\mathrm{N}, \mathrm{C}, \mathrm{O}, \mathrm{Zn}, \mathrm{Mg}$, etc. ( $\mathrm{F}$ ) $\mathrm{X}$-ray diffraction (XRD) pattern of freshly prepared blue luminescent CDs from prunes, which also confirms the presence of graphitic carbon, Zn, 
Table 1 Size distribution of blue-colored fluorescent LCDs from prunes, acid-functionalized magnetic nanoparticles and multifunctional prune-based LCDs

\begin{tabular}{lcc}
\hline Nanoparticle description & $\begin{array}{l}\text { Size measured } \\
\text { by DLS }\end{array}$ & $\begin{array}{l}\text { Size measured } \\
\text { by TEM }\end{array}$ \\
\hline $\begin{array}{l}\text { Prune-based LCDs } \\
\begin{array}{l}\text { Acid-functionalized } \\
\text { magnetic nanoparticles }\end{array}\end{array}$ & $7 \pm \pm 10 \mathrm{~nm}$ & $8 \pm 2 \mathrm{~nm}$ \\
$\begin{array}{l}\text { Multifunctional } \\
\text { prune-based LCDs }\end{array}$ & $58 \pm 12 \mathrm{~nm}$ & $55 \pm 10 \mathrm{~nm}$ \\
& &
\end{tabular}

several different types of C-binding site, namely, $-\mathrm{CN}, \mathrm{C}=\mathrm{O}$, $\mathrm{C}-\mathrm{C}$ and $\mathrm{COO}$.

Fig. 1D shows the Fourier transform infrared (FTIR) spectrum of freshly prepared LCDs from prunes, which indicates the presence of several different types of surface functional group such as $-\mathrm{NH},-\mathrm{OH}, \mathrm{C}=\mathrm{O}, \mathrm{C}=\mathrm{N},-\mathrm{N}=\mathrm{C}=\mathrm{O}$, etc. The reported FTIR spectrum exhibits a clear peak at $\sim 3650 \mathrm{~cm}^{-1}$, which corresponds to $-\mathrm{NH}$ stretching vibrations. Similarly, we also observed a vibration band at $\sim 3280 \mathrm{~cm}^{-1}$, which corresponds to the absorption band due to $\mathrm{O}-\mathrm{H}$ stretching. The other FTIR bands observed at $\sim 3020 \mathrm{~cm}^{-1}, \sim 2450 \mathrm{~cm}^{-1}, \sim 2270 \mathrm{~cm}^{-1}$, $\sim 1980 \mathrm{~cm}^{-1}, \sim 1100 \mathrm{~cm}^{-1}$ and $\sim 780 \mathrm{~cm}^{-1}$ correspond to carboxylic acid $-\mathrm{OH}$ stretching, $\mathrm{C} \equiv \mathrm{N}$ stretching, $-\mathrm{N}=\mathrm{C}=\mathrm{O}$ stretching, acid $\mathrm{C}=\mathrm{O}$ stretching, amine $\mathrm{C}-\mathrm{N}$ stretching, and $-\mathrm{NH}$ bending vibrations, respectively. Fig. $1 \mathrm{~F}$ shows the powder $\mathrm{X}$-ray diffraction (XRD) pattern of freshly prepared blue luminescent CDs from prunes, which also confirms the presence of graphitic carbon, $\mathrm{Zn}, \mathrm{Mg}$ and $\mathrm{Si}$, as all the peaks match the JCPDS XRD peaks for $\mathrm{ZnO}, \mathrm{MgO}, \mathrm{SiO}_{2}$ and graphitic carbon. To understand the luminescence behavior, we also recorded the luminescence spectrum at an excitation wavelength of $380 \mathrm{~nm}$. Fig. 1G shows the absorption spectrum of freshly prepared CDs from prunes, which exhibits a strong absorption peak at $282 \mathrm{~nm}$. The observed peak can be attributed to $\pi \rightarrow \pi^{*}$ transitions in $\mathrm{C}=\mathrm{C}$ bonds and $\mathrm{n} \rightarrow \pi^{*}$ transitions in $\mathrm{C}=\mathrm{O}$ bonds. As shown in Fig. $1 \mathrm{H}$, the emission spectrum of freshly prepared LCDs from prunes at an excitation wavelength of $380 \mathrm{~nm}$ displays a broad emission from the prune-based LCDs with an emission maximum ( $\lambda_{\max }$ of emission) around $450 \mathrm{~nm}$. The photograph in the inset of Fig. 1H shows that freshly prepared LCDs from prunes exhibited blue fluorescence when excited at $380 \mathrm{~nm}$ with UV light. Using quinine sulfate as a standard (QY = $54 \%$ ), we determined that the photoluminescence quantum yield of freshly prepared blue luminescent LCDs from prunes was 0.36 at an excitation wavelength of $380 \mathrm{~nm}$. Fig. 1I shows that the photoluminescence spectrum of freshly prepared CDs from prunes can be changed by varying the excitation energy. Although the exact origin of the excitation-dependent single- photon luminescence from freshly prepared CDs from prunes is not known, it may be due to ground-state heterogeneity due to their polydispersity. In addition, there is the possibility of multiple discrete electronic states owing to the presence of different types of aggregate. Fig. 1J shows the luminescence spectra of freshly prepared CDs from prunes at various $\mathrm{pH}$ values, which indicate that there were slight changes in intensity as well as in the wavelength of the luminescence maximum as the $\mathrm{pH}$ was varied from acidic to basic.

\section{Design of green fluorescent LCDs from mangoes}

Green fluorescent LCDs were synthesized by the hydrothermal treatment of mangoes using $\mathrm{H}_{3} \mathrm{PO}_{4}$. The experimental details are described in the experimental section. In this case, we used a very similar experimental procedure to that used for prunes. For this purpose, ripe mangoes were dissolved in water and $\mathrm{H}_{3} \mathrm{PO}_{4}$. After sonication for $5 \mathrm{~min}$, the solution was put in an autoclave and heated at $200{ }^{\circ} \mathrm{C}$ for $2 \mathrm{~h}$. The product was then neutralized with $\mathrm{NaOH}$.

Finally, the product was dialyzed against water for $72 \mathrm{~h}$ and then filtered. The green fluorescent carbon dots were further purified by dialysis and then stored at $4{ }^{\circ} \mathrm{C}$. After the synthesis, we purified the particles using silica column chromatography. Finally, the mango-based LCDs with green emissions were characterized by HR-TEM, EDX, FTIR, and fluorescence spectroscopy and DLS measurements, as reported in Fig. 2A-J. Fig. 2A shows a TEM image of freshly prepared LCDs from mangoes, which indicates that the size of the mango-based LCDs was $6 \pm 2 \mathrm{~nm}$. Fig. 2B and Table 2 report the DLS data, which also indicate that the average size of freshly prepared LCDs from mangoes was about $5 \pm 2 \mathrm{~nm}$, which matches the TEM data quite well. The HR-TEM image of a single particle of freshly prepared LCDs from mangoes in the inset of Fig. 2A shows well-resolved lattice fringes with an interplanar spacing of $0.36 \mathrm{~nm}$, which is similar to that of the (020) diffraction facets of graphitic carbon. The observed spacing is slightly larger than that of bulk graphite, which is $0.334 \mathrm{~nm}$. This is due to the presence of functional groups and nitrogen, $\mathrm{P}, \mathrm{Cu}, \mathrm{Mn}$ and other dopant atoms, which increased the basal plane spacing. Fig. 2C shows the XPS spectrum of freshly prepared green luminescent $\mathrm{CDs}$ from mangoes, which indicates the presence of $\mathrm{P}, \mathrm{C}, \mathrm{N}, \mathrm{O}, \mathrm{Cu}$ and $\mathrm{Mn}$ by the presence of peaks due to $\mathrm{P}_{2 \mathrm{p}}$ (8.0\%), $\mathrm{C}_{1 \mathrm{~s}}(19 \%), \mathrm{O}_{1 \mathrm{~s}}(36 \%), \mathrm{N}_{1 \mathrm{~s}}(6 \%), \mathrm{Na}_{1 \mathrm{~s}}(12 \%), \mathrm{Mn}_{2 \mathrm{p}}(6.0 \%)$ and $\mathrm{Cu}_{2 \mathrm{p}}(12 \%)$. EDX elemental mapping of freshly prepared LCDs from mangoes, as reported in Fig. 2E, indicates the presence of $\mathrm{P}, \mathrm{N}, \mathrm{C}, \mathrm{O}, \mathrm{Na}, \mathrm{Mn}, \mathrm{Cu}$, etc. The EDX elemental analysis data closely match the XPS analysis data. Highresolution XPS analysis indicates the presence of several different types of C-binding site, namely, $-\mathrm{CN}, \mathrm{C}=\mathrm{O}, \mathrm{C}-\mathrm{C}$, and COO. Fig. 2D shows the FTIR spectrum of freshly prepared

Mg and Si. (G) UV-vis absorption spectra of freshly prepared CDs from prunes, magnetic nanoparticles and CDs attached to magnetic nanoparticles. $(\mathrm{H})$ Emission spectra of freshly prepared CDs from prunes and CDs attached to magnetic nanoparticles at an excitation wavelength of $380 \mathrm{~nm}$. The inset photograph shows the blue-colored emission from freshly prepared CDs from prunes in the presence of UV light. (I) Excitation wavelength-dependent emission spectra of freshly prepared CDs from prunes. (J) Emission spectra of freshly prepared CDs from prunes at different $\mathrm{pH}$ values. 

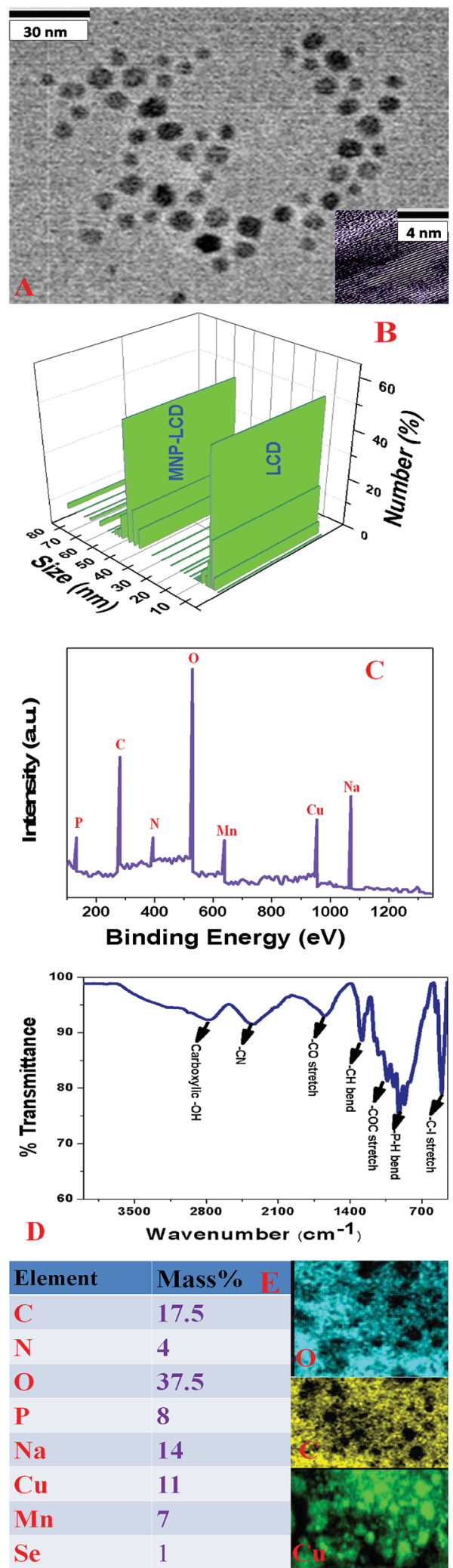
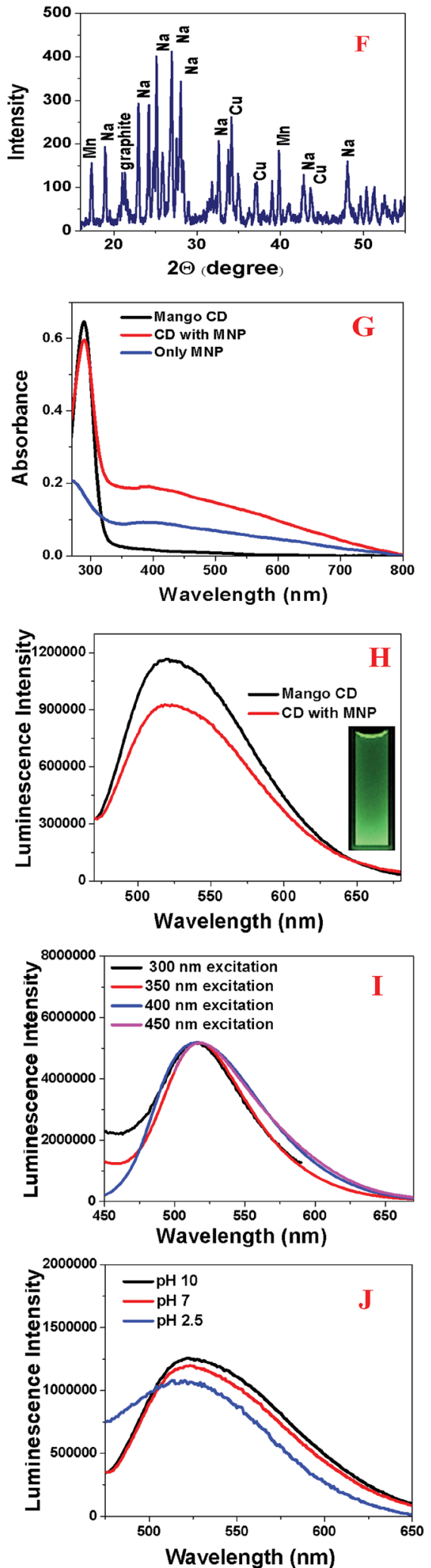

Fig. 2 (A) TEM image of freshly prepared green luminescent CDs from mangoes. Inset: HR-TEM image of a single particle showing well-resolved lattice fringes with an interplanar spacing of $0.36 \mathrm{~nm}$, which are due to graphitic carbon. (B) DLS data showing a histogram of the size distributions of freshly prepared green luminescent CDs from mangoes and LCDs attached to magnetic nanoparticles. (C) XPS spectrum of freshly prepared blue luminescent CDs from mangoes showing peaks due to $\mathrm{P}, \mathrm{C}, \mathrm{N}, \mathrm{O}, \mathrm{Mn}, \mathrm{Cu}$ and $\mathrm{Na}$ at 128.5, 284.8, 398, 530, 638.7, 933 and 1071 eV, respectively. (D) FTIR spectrum of freshly prepared LCDs from mangoes showing the presence of different types of surface functional group, such as carboxylic $-\mathrm{OH}, \mathrm{C}=\mathrm{O}, \mathrm{C}=\mathrm{N},-\mathrm{P}-\mathrm{H},-\mathrm{C}-\mathrm{I}$, etc. (E) EDX elemental mapping of freshly prepared LCDs from mangoes showing the presence of $\mathrm{P}, \mathrm{C}, \mathrm{O}, \mathrm{Se}, \mathrm{Cu}, \mathrm{Mn}$, etc. (F) X-ray diffraction (XRD) pattern of freshly prepared blue luminescent $\mathrm{CDs}$ from mangoes, which also 
Table 2 Size distribution of green-colored fluorescent LCDs from mangoes, acid-functionalized magnetic nanoparticles and multifunctional mango-based LCDs

\begin{tabular}{lcc}
\hline Nanoparticle description & $\begin{array}{l}\text { Size measured } \\
\text { by DLS }\end{array}$ & $\begin{array}{l}\text { Size measured } \\
\text { by TEM }\end{array}$ \\
\hline $\begin{array}{l}\text { Mango-based LCDs } \\
\begin{array}{l}\text { Acid-functionalized } \\
\text { magnetic nanoparticles }\end{array}\end{array}$ & $\begin{array}{l}5 \pm 2 \mathrm{~nm} \\
\begin{array}{l}\text { Multifunctional } \\
\text { mango-based LCDs }\end{array}\end{array}$ & $48 \pm 10 \mathrm{~nm}$ \\
& & $40 \pm 5 \mathrm{~nm}$ \\
\end{tabular}

LCDs from mangoes, which shows the presence of several different types of surface functional group, such as $-\mathrm{PH}, \mathrm{C}=\mathrm{O}$, $\mathrm{C}=\mathrm{N},-\mathrm{C}-\mathrm{I}$, carboxylic $-\mathrm{OH}$, etc. Fig. $2 \mathrm{~F}$ shows the powder X-ray diffraction (XRD) pattern of freshly prepared green luminescent CDs, which also confirms the presence of graphitic carbon, Na, $\mathrm{Cu}$ and $\mathrm{Mg}$, as all the peaks match the JCPDS XRD peaks for sodium phosphate, $\mathrm{MgO}, \mathrm{CuO}$ and graphitic carbon.

Fig. 2G shows the absorption spectrum of freshly prepared CDs from mangoes, which displays a strong absorption peak at $292 \mathrm{~nm}$. The observed peak can be attributed to $\pi \rightarrow \pi^{*}$ transitions in $\mathrm{C}=\mathrm{C}$ bonds and $\mathrm{n} \rightarrow \pi^{*}$ transitions in $\mathrm{C}=\mathrm{O}$ bonds. Fig. $2 \mathrm{H}$ shows the emission spectrum of freshly prepared LCDs from mangoes at an excitation wavelength of $380 \mathrm{~nm}$, which displays a broad emission from the mango-based LCDs with an emission maximum ( $\lambda_{\max }$ of emission) around $530 \mathrm{~nm}$. The photograph in the inset of Fig. $2 \mathrm{H}$ shows that freshly prepared LCDs from mangoes exhibited green fluorescence when excited at $380 \mathrm{~nm}$ with UV light. Using quinine sulfate as a standard (QY $=54 \%$, we determined that the quantum yield of green fluorescent LCDs from mangoes was 0.61 at an excitation wavelength of $380 \mathrm{~nm}$. Fig. 2I shows the excitation wavelengthdependent photoluminescence spectra of freshly prepared CDs from mangoes, which indicate that the luminescence spectrum was unchanged when we varied the excitation wavelength from $300 \mathrm{~nm}$ to $450 \mathrm{~nm}$. Fig. 2J shows the luminescence spectra of freshly prepared CDs from mangoes at various $\mathrm{pH}$ values, which indicate that there were slight changes in intensity as the $\mathrm{pH}$ was varied from acidic to basic.

\section{Design of antibody-conjugated blue/green fluorescent multifunctional magnetic fruit-based LCD nanosystems}

To detect breast cancer heterogeneity via the selective separation and accurate identification of TNBC and HER-2(+) or ER/ $\mathrm{PR}(+)$ breast cancer cells from blood, we have developed antibody-conjugated multifunctional multicolor-fluorescence magnetic LCD-based nanosystems.

For the development of a multifunctional multicolorfluorescence nanoprobe, at first we synthesized carboxylic acid-functionalized magnetic nanoparticles using a coprecipitation method from ferric chloride and 1,6-hexanedioic acid, as we reported previously, as shown in Scheme $1 \mathrm{~B} \cdot{ }^{15,16,30}$ After that, the black precipitate comprising magnetic $\mathrm{Fe}_{3} \mathrm{O}_{4}$ nanoparticles was separated from the supernatant using a neodymium magnet. In the next step, the acid-functionalized magnetic nanoparticles were characterized by HR-TEM and DLS. The HR-TEM image in Fig. 3A shows that the acidfunctionalized magnetic nanoparticles had an average size of about $40 \pm 5 \mathrm{~nm}$, which matches the data from DLS measurements, as reported in Tables 1 and 2, quite well. To determine the superparamagnetic properties of the acid-functionalized magnetic nanoparticles, we used a SQUID magnetometer, ${ }^{17-19,29,46,49}$ which indicated that the specific saturation magnetization was $36.2 \mathrm{emu} \mathrm{g}^{-1}$. As shown in Scheme $1 \mathrm{~B}$, in the next step we carried out EDC-mediated esterification for the development of acid-functionalized magnetic nanoparticles attached to blue/green fluorescent LCDs using a reported method that we have described previously. ${ }^{17-29}$ After that, the ester-coupled blue/green fluorescent LCDs attached to multifunctional magnetic nanoparticles were separated by a magnet, as shown in Fig. 3D. After the magnetic separation, the multifunctional nanosystems were washed several times with water to remove excess LCDs. As shown in Fig. 3B, an HR-TEM image indicates that the size of our green fluorescent LCDs attached to a magnetic nanosystem was $48 \pm 8 \mathrm{~nm}$, which matches the results of DLS measurements, as reported in Table 2 and Fig. 2B, quite well. Similarly, as shown in Fig. 3C, an HR-TEM image indicates that the size of our blue fluorescent LCDs attached to a magnetic nanosystem was $55 \pm 10 \mathrm{~nm}$, which matches the results of DLS measurements, as reported in Table 1 and Fig. 1B, quite well. We also measured the zeta potentials of magnetic nanoparticles and green luminescent CDs attached to magnetic nanoparticles separately, which indicated that the zeta potential of magnetic nanoparticles peaked at $1.84 \pm$ $0.65 \mathrm{mV}$, whereas the zeta potential of green luminescent CDcoated magnetic nanoparticles peaked at $-1.52 \pm 0.43 \mathrm{mV}$. Fig. 3E shows the EDX data for green fluorescent LCDs attached to magnetic nanoprobes, which clearly show the presence of $\mathrm{Fe}, \mathrm{C}, \mathrm{O}, \mathrm{Mg}, \mathrm{K}$, etc. To determine the loading amounts of LCDs, we performed thermogravimetric analysis (TGA), as shown in Fig. 3F. From the TGA data we estimated that the weight percentage of blue fluorescent LCDs in the fluorescent magnetic composite was about $14 \pm 3 \%$. Similarly, from TGA experiments we estimated that the weight percentage of green fluorescent LCDs in the fluorescent magnetic composite was about $19 \pm 3 \%$. Fig. $1 \mathrm{G}$ and $2 \mathrm{G}$ show the absorption spectra of LCDs attached to magnetic nanoparticles, which exhibit peaks for LCDs as well as for magnetic nanoparticles. Fig. $1 \mathrm{H}$ shows the luminescence spectrum of blue fluorescent LCDs attached to magnetic nanoprobes, which indicates that

confirms the presence of graphitic carbon, $\mathrm{Na}, \mathrm{Cu}$ and $\mathrm{Mn}$. (G) UV-vis absorption spectra of freshly prepared CDs from mangoes, magnetic nanoparticles and CDs attached to magnetic nanoparticles. $(\mathrm{H})$ Emission spectra of freshly prepared CDs from mangoes and CDs attached to magnetic nanoparticles at an excitation wavelength of $380 \mathrm{~nm}$. The inset photograph shows the green-colored emission from freshly prepared CDs from mangoes in the presence of UV light. (I) Excitation wavelength-dependent emission spectra of freshly prepared CDs from mangoes. (J) Emission spectra of freshly prepared CDs from mangoes at different $\mathrm{pH}$ values. 
fluorescence quenching of $13 \pm 2 \%$ occurred after modification with magnetic nanoparticles. Similarly, Fig. $2 \mathrm{H}$ shows the luminescence spectrum of green fluorescent LCDs attached to magnetic nanoprobes, which indicates that fluorescence quenching of $16 \pm 2 \%$ occurred after modification with magnetic nanoparticles. The measurements of superparamagnetic properties indicate that the specific saturation magnetization was $30.2 \mathrm{emu} \mathrm{g}^{-1}$ for the blue fluorescent LCDs attached to magnetic nanoprobes and $27.8 \mathrm{emu} \mathrm{g}^{-1}$ for the green fluorescent LCDs attached to magnetic nanoprobes.

Finally, for the selective separation and accurate identification of TNBC and HER-2(+) or ER/PR(+) breast cancer cells from blood, we developed antibody-conjugated multifunctional multicolor-fluorescence magnetic LCD-based nanosystems. For this purpose, we developed amine-conjugated polyethylene glycol $\left(\mathrm{NH}_{2}\right.$-PEG) attached to a blue/green fluorescent magnetic LCD-based nanosystem, and then a TNBC-targeted anti-AXL antibody was attached to a green fluorescent magnetic LCDbased nanosystem by our previously reported method..$^{14,15,30}$ Similarly, for the selective separation and imaging of HER-2(+) SK-BR-3 cells, we developed an anti-HER-2 antibody attached to a blue fluorescent magnetic LCD-based nanosystem using the above procedure. On the other hand, for the selective separation and imaging of estrogen receptor (ER)(+) MCF-7 cells, an antiERa antibody attached to a blue fluorescent magnetic LCDbased nanosystem was developed. We also measured the zeta
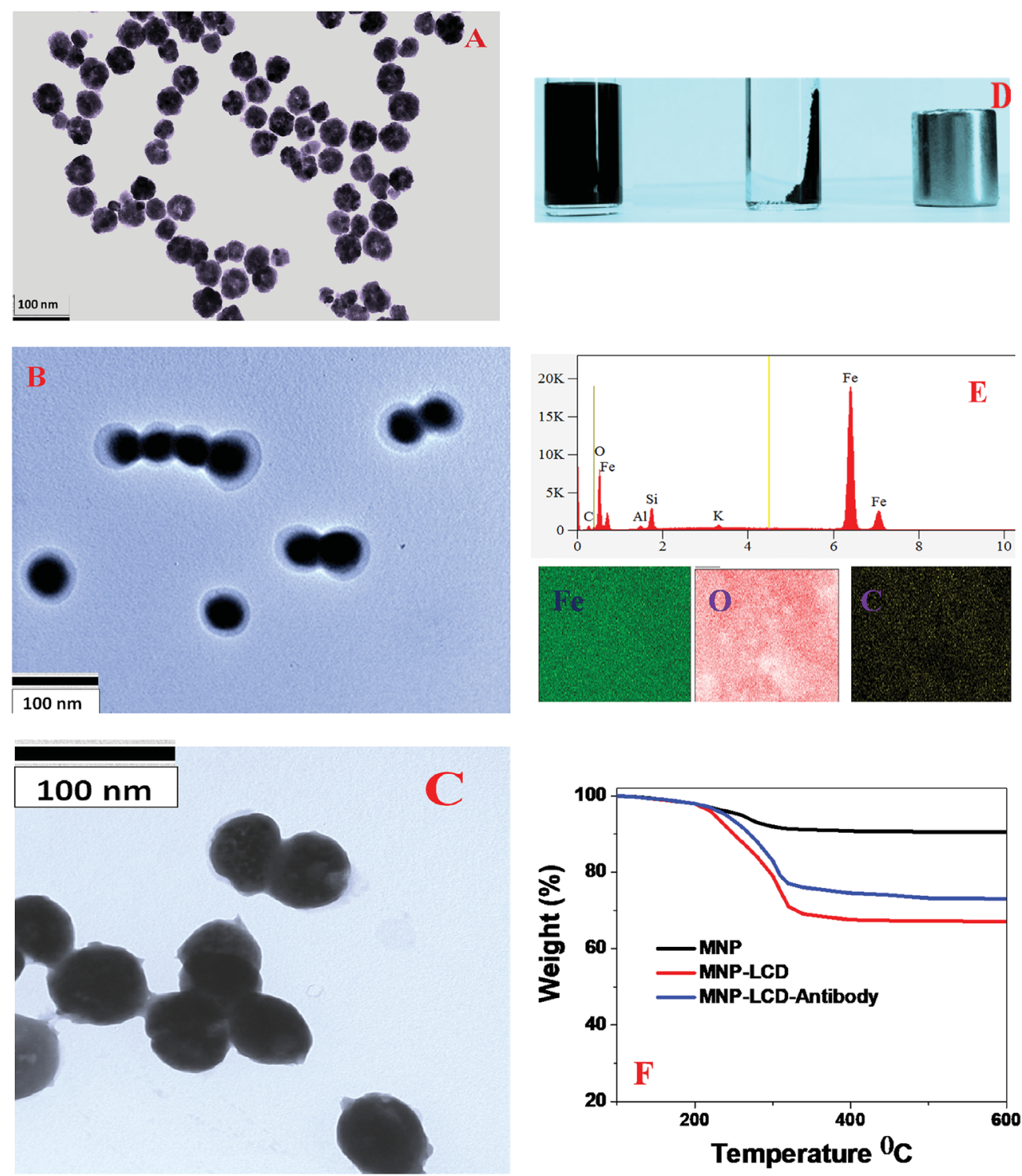

Fig. 3 (A) TEM image of freshly prepared acid-functionalized magnetic nanoparticles. (B) TEM image of freshly prepared green fluorescent LCDs attached to a multifunctional magnetic nanosystem. (C) TEM image of freshly prepared blue fluorescent LCDs attached to a multifunctional magnetic nanosystem. (D) Photograph showing highly paramagnetic green fluorescent LCDs attached to a multifunctional nanosystem, which can be separated very easily using a small bar magnet. (E) EDX elemental mapping of freshly prepared green fluorescent LCDs attached to a multifunctional magnetic nanosystem showing the presence of $\mathrm{Fe}, \mathrm{C}, \mathrm{O}, \mathrm{Mg}$, etc. (F) Thermogravimetric analysis (TGA) profiles for freshly prepared magnetic nanoparticles, blue fluorescent LCDs and blue fluorescent LCDs attached to a multifunctional magnetic nanosystem. 
potentials of magnetic nanoparticles, blue luminescent CDs attached to magnetic nanoparticles and antibody-conjugated blue luminescent CDs attached to magnetic nanoparticles separately. The experimental measurements indicated that the zeta potential of magnetic nanoparticles peaked at $1.84 \pm$ $0.65 \mathrm{mV}$, whereas the zeta potential of blue luminescent CDcoated magnetic nanoparticles peaked at $-1.98 \pm 0.63 \mathrm{mV}$. On the other hand, the zeta potential of the antibodyconjugated nanoplatform peaked at $-3.25 \pm 0.81 \mathrm{mV}$.

To determine the loading amounts of the antibodies, we performed thermogravimetric analysis, as shown in Fig. 3F. From the TGA data we estimated that the weight percentage of the antibodies in the fluorescent magnetic composite was about $4.5 \pm 1 \%$. Similarly, from TGA experiments we estimated that the weight percentage of green fluorescent LCDs in the fluorescent magnetic composite was about $5.8 \pm 1 \%$.
Determining the possible toxicity and photostability of the blue/green fluorescent magnetic LCD-based nanosystems

To determine the possible toxicity of our blue/green fluorescent magnetic LCD-based nanosystems, we incubated an antibody attached to a blue/green fluorescent magnetic LCD-based nanosystem with $1.2 \times 10^{5}$ cells per $\mathrm{mL}$ normal HaCaT skin cells, HER-2(+) SK-BR-3 cells, MDA-MB-231 TNBC cells and LNCaP human prostate cancer cells separately for $24 \mathrm{~h}$. After that, the numbers of live breast cancer, prostate cancer and normal skin cells were measured using an MTT test. ${ }^{16-19,29,46,49}$ Fig. 4A shows the excellent biocompatibility of the blue fluorescent magnetic LCD-based nanosystem for breast cancer, prostate cancer and normal skin cells, as more than $98 \%$ of cells were alive after incubation for one day. Similarly, Fig. 4B shows the excellent biocompatibility of the green fluorescent magnetic LCD-based nanosystem for breast cancer, prostate cancer and
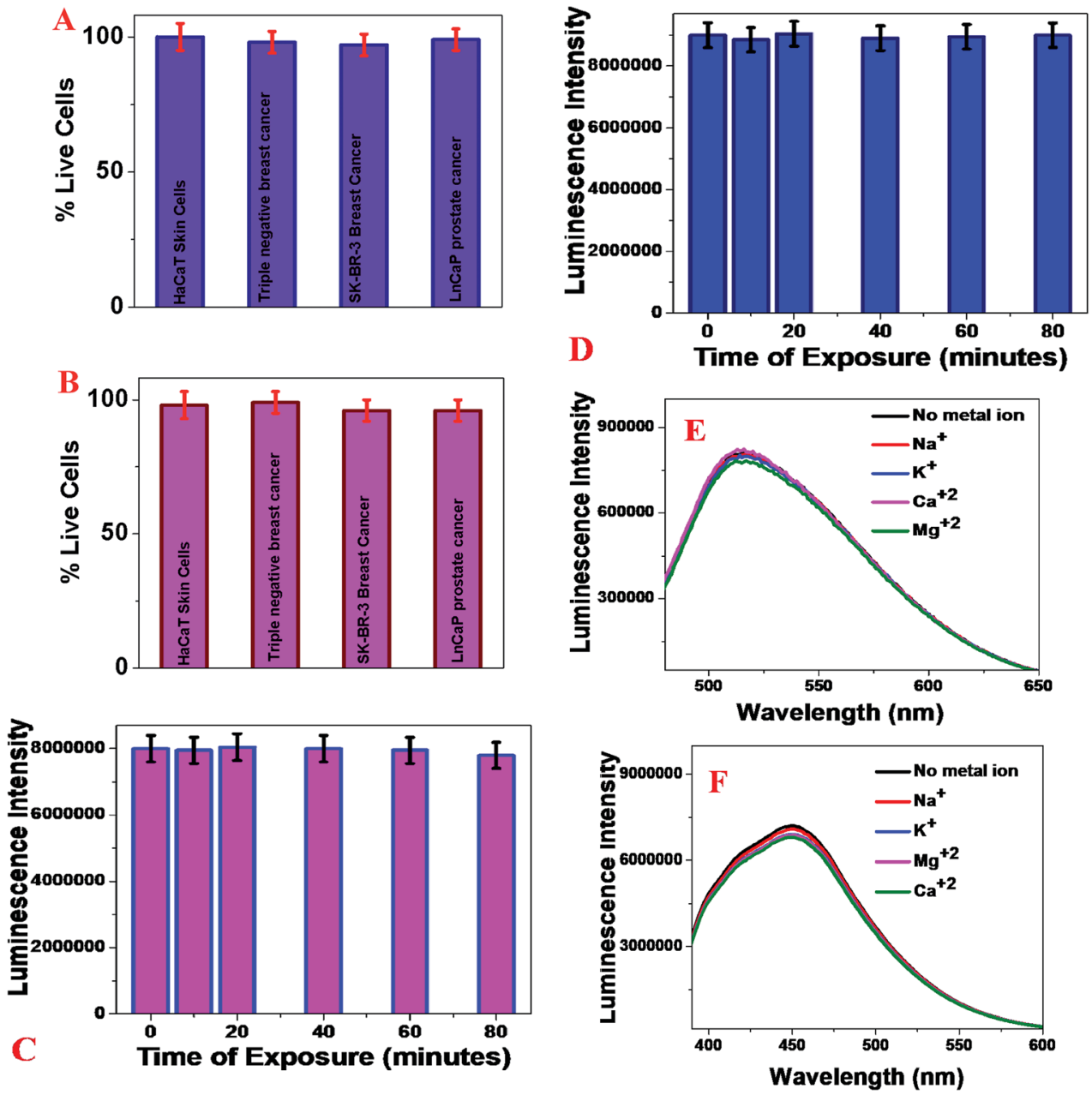

Fig. 4 (A) Viability of different breast cancer, prostate cancer and normal skin cells treated with the blue fluorescent magnetic LCD-based nanosystem. The error bars represent the standard deviation $(n=3)$. (B) Viability of different breast cancer, prostate cancer, and normal skin cells treated with the green fluorescent magnetic LCD-based nanosystem. The error bars represent the standard deviation ( $n=3$ ). (C) Fluorescence intensity of anti-AXL antibody attached to a green fluorescent magnetic LCD-based nanosystem as a function of time. The error bars represent the standard deviation ( $n=3$ ). (D) Fluorescence intensity of anti-HER-2 antibody attached to a blue fluorescent magnetic LCD-based nanosystem as a function of time. The error bars represent the standard deviation $(n=3)$. (E) Plot showing the influence of metal ions on the luminescence spectrum of green LCDs attached to magnetic nanoparticles. (F) Plot showing the influence of metal ions on the luminescence spectrum of blue LCDs attached to magnetic nanoparticles. 
normal skin cells, as more than $97 \%$ of cells were alive after incubation for one day.

Next, to determine the photostability of our developed blue/ green fluorescent magnetic LCD-based nanosystems, timedependent luminescence experiments were performed at an excitation wavelength of $380 \mathrm{~nm}$ for an exposure time of $80 \mathrm{~min}$. Fig. $4 \mathrm{C}$ shows the excellent photostability of the blue fluorescent magnetic LCD-based nanosystem, of which the luminescence intensity changed by less than $8 \%$ even after exposure to light for $80 \mathrm{~min}$. Similarly, Fig. 4D shows the excellent photostability of the green fluorescent magnetic LCD-based nanosystem, of which the luminescence intensity changed by less than $6 \%$ even after exposure to light for $80 \mathrm{~min}$. Because blood contains several metal ions that may influence the luminescence spectra of CDs, we performed several luminescence experiments on LCDs attached to magnetic nanoparticles in the presence of different metal ions. As shown in Fig. 4E and F, we did not observe any significant changes in the luminescence intensity of green and blue luminescent LCDs attached to magnetic nanoparticles in the presence of $\mathrm{Na}^{+}, \mathrm{K}^{+}, \mathrm{Mg}^{2+}$ and $\mathrm{Ca}^{2+}$.

\section{Selective capture and identification of TNBC cells from infected blood and cell mixtures using an anti-AXL antibody attached to a green fluorescent magnetic LCD-based nanosystem}

To determine whether an anti-AXL antibody attached to a green fluorescent magnetic LCD-based nanosystem can be used for the selective capture and identification of TNBC cells from infected blood and cell mixtures, $10^{5}$ cells per mL of HER-2(-) ER(-) MDA-MB-231 cells, $10^{5}$ cells per mL of HER-2(+) SK-BR-3 cells and $10^{5}$ cells per mL of ER(+) MCF-7 cells were incubated with $10 \mathrm{~mL}$ citrated whole rabbit blood. In the next step, we added $10^{6}$ cells per $\mathrm{mL}$ peripheral blood mononuclear cells (PBMCs) to the mixture, which was gently shaken for more than $90 \mathrm{~min}$. After that, different concentrations of an anti-AXL antibody attached to a green fluorescent magnetic LCD-based nanosystem were added to the infected blood sample and mixed continuously for $40 \mathrm{~min}$. After that, the targeted cells bound to the anti-AXL antibody attached to the green fluorescent magnetic LCD-based nanosystem were separated using a bar magnet. In the next step, the targeted cells bound to the anti-AXL antibody attached to the green fluorescent magnetic LCD-based nanosystem were characterized using an enzymelinked ELISA kit, TEM and fluorescence mapping analysis, as shown in Fig. 5. As shown in Fig. 5A, ELISA experimental data show that the capture efficiency for TNBC cells was greater than $97 \%$ when we used the anti-AXL antibody attached to a green fluorescent magnetic LCD-based nanosystem. On the other hand, the capture efficiency for HER-2(+) SK-BR-3 cells and ER $(+)$ MCF-7 cells was less than $3 \%$ when we used the anti-AXL antibody attached to a green fluorescent magnetic LCD-based nanosystem. Fig. 5D shows a TEM image of magnetically separated cells, which shows that the anti-AXL antibody attached to a green fluorescent magnetic LCD-based nanosystem was on the surface of the MDA-MB-231 cells that were separated by the magnet.
Fig. 5E shows a green single-photon luminescence image of magnetically captured cells, which indicates that MDA-MB-231 cells were captured by the anti-AXL antibody attached to a green fluorescent magnetic LCD-based nanosystem. Our reported data show that the anti-AXL antibody attached to a green fluorescent magnetic LCD-based nanosystem can be used for imaging TNBC cells via a very bright green emission after magnetic separation. The bright-field image shown in Fig. 5F shows that HER-2(+) SK-BR-3 cells, ER(+) MCF-7 cells, peripheral blood mononuclear cells and rabbit blood cells did not bind to the anti-AXL antibody attached to a green fluorescent magnetic LCD-based nanosystem. Similarly, a single-photon fluorescence image of the supernatant indicates that HER-2(+) SK-BR-3 cells, ER $(+)$ MCF-7 cells, peripheral blood mononuclear cells and rabbit blood cells did not bind to the anti-AXL antibody attached to a green fluorescent magnetic LCD-based nanosystem. As a result, we did not observe any luminescence image from the supernatant after magnetic separation. All the reported data clearly indicate that the anti-AXL antibody attached to a green fluorescent magnetic LCD-based nanosystem is highly specific for TNBC cells and can be used for the targeted separation and imaging of MDA-MB-231 and TNBC cells.

\section{Selective capture and identification of HER-2(+) SK-BR-3 breast cancer cells from infected blood and cell mixtures using an anti-HER-2 antibody attached to a blue fluorescent magnetic LCD-based nanosystem}

Next, to determine whether an anti-HER-2 antibody attached to a blue fluorescent magnetic LCD-based nanosystem can be used for the selective capture and identification of HER-2(+) breast cancer cells from infected blood and cell mixtures, $10^{5}$ cells per $\mathrm{mL}$ of HER-2(-) ER(-) MDA-MB-231 cells, $10^{5}$ cells per $\mathrm{mL}$ of HER-2(+) SK-BR-3 cells and $10^{5}$ cells per mL of ER(+) MCF-7 cells were incubated with $10 \mathrm{~mL}$ citrated whole rabbit blood. In the next step, we added $10^{6}$ cells per $\mathrm{mL}$ of peripheral blood mononuclear cells (PBMCs) to the mixture and subjected it to gentle shaking for more than $90 \mathrm{~min}$. After that, different concentrations of an anti-HER-2 antibody attached to a blue fluorescent magnetic LCD-based nanosystem were added to the infected blood sample and mixed continuously for $40 \mathrm{~min}$. After that, the targeted cells bound to the anti-HER-2 antibody attached to the blue fluorescent magnetic LCD-based nanosystem were separated using a bar magnet. In the next step, the targeted cells bound to the anti-HER-2 antibody attached to the green fluorescent magnetic LCD-based nanosystem were characterized using an ELISA kit and fluorescence mapping analysis, as shown in Fig. 5 and 6.

As shown in Fig. 5B, ELISA experimental data show that the capture efficiency for HER-2(+) SK-BR-3 cells was greater than 98\% when we used an anti-HER-2 antibody attached to a blue fluorescent magnetic LCD-based nanosystem. On the other hand, the capture efficiency for HER-2(-) and ER(-) MDA-MB231 and ER(+) MCF-7 cells was less than $4 \%$ when we used an anti-HER-2 antibody attached to a blue fluorescent magnetic LCD-based nanosystem. Fig. 6A shows a blue single-photon luminescence image of magnetically captured cells, which 

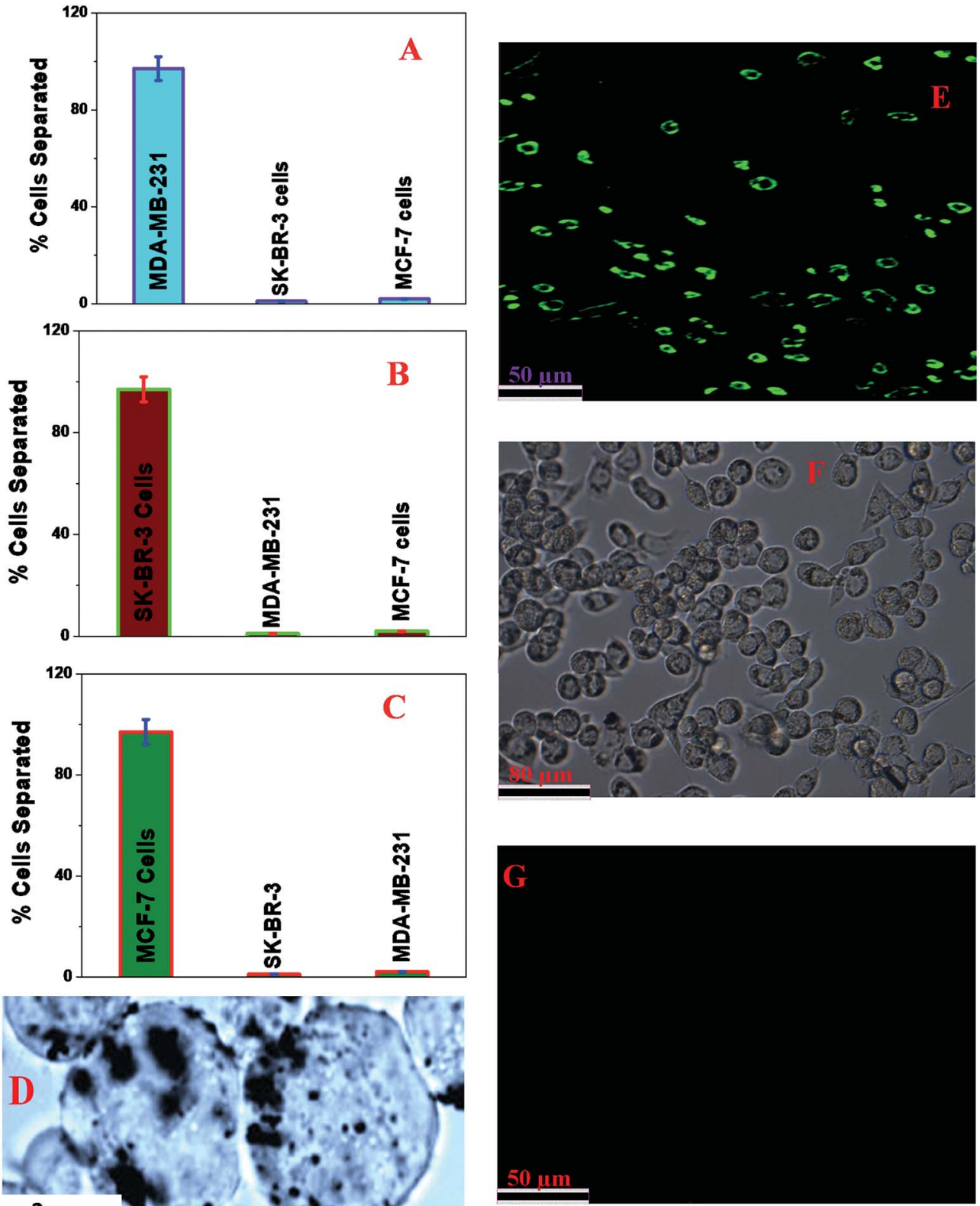

Fig. 5 (A) Percentages of HER-2(-) ER(-) MDA-MB-231 cells, HER-2(+) SK-BR-3 cells and ER(+) MCF-7 cells captured by an anti-AXL antibody attached to a green fluorescent magnetic LCD-based nanosystem. The error bars represent the standard deviation $(n=3)$. (B) Percentages of HER-2(-) ER(-) MDA-MB-231 cells, HER-2(+) SK-BR-3 cells and ER(+) MCF-7 cells captured by an anti-HER-2 antibody attached to a blue fluorescent magnetic LCD-based nanosystem. The error bars represent the standard deviation $(n=3)$. (C) Percentages of HER-2(-) ER(-) MDAMB-231 cells, HER-2(+) SK-BR-3 cells and ER(+) MCF-7 cells captured by an anti-ERa antibody attached to a blue fluorescent magnetic LCDbased nanosystem. The error bars represent the standard deviation $(n=3)$. (D) TEM image showing an anti-AXL antibody attached to a green fluorescent magnetic LCD-based nanosystem on the surface of MDA-MB-231 cells after magnetic separation. (E) Single-photon luminescence image showing MDA-MB-231 cells captured by an anti-AXL antibody attached to a green fluorescent magnetic LCD-based nanosystem. (F) Bright-field image of HER-2(+) SK-BR-3 cells, ER(+) MCF-7 cells, peripheral blood mononuclear cells and rabbit blood cells, which did not bind to an anti-AXL antibody attached to a green fluorescent magnetic LCD-based nanosystem. (G) Single-photon fluorescence image of supernatant indicating that HER-2(+) SK-BR-3 cells, ER(+) MCF-7 cells, peripheral blood mononuclear cells and rabbit blood cells did not bind to an anti-AXL antibody attached to a green fluorescent magnetic LCD-based nanosystem.

indicates that HER-2(+) SK-BR-3 cells were captured by the antiHER-2 antibody attached to a blue fluorescent magnetic LCDbased nanosystem. Our reported data show that the anti-HER2 antibody attached to a blue fluorescent magnetic LCD-based nanosystem can be used for imaging HER-2(+) cancer cells via a very bright green emission after magnetic separation. All the reported data clearly indicate that the anti-HER-2 antibody attached to a blue fluorescent magnetic LCD-based nanosystem is highly specific for HER-2(+) SK-BR-3 cells and can be used for the targeted separation and imaging of HER-2(+) SK-BR-3 cells. 

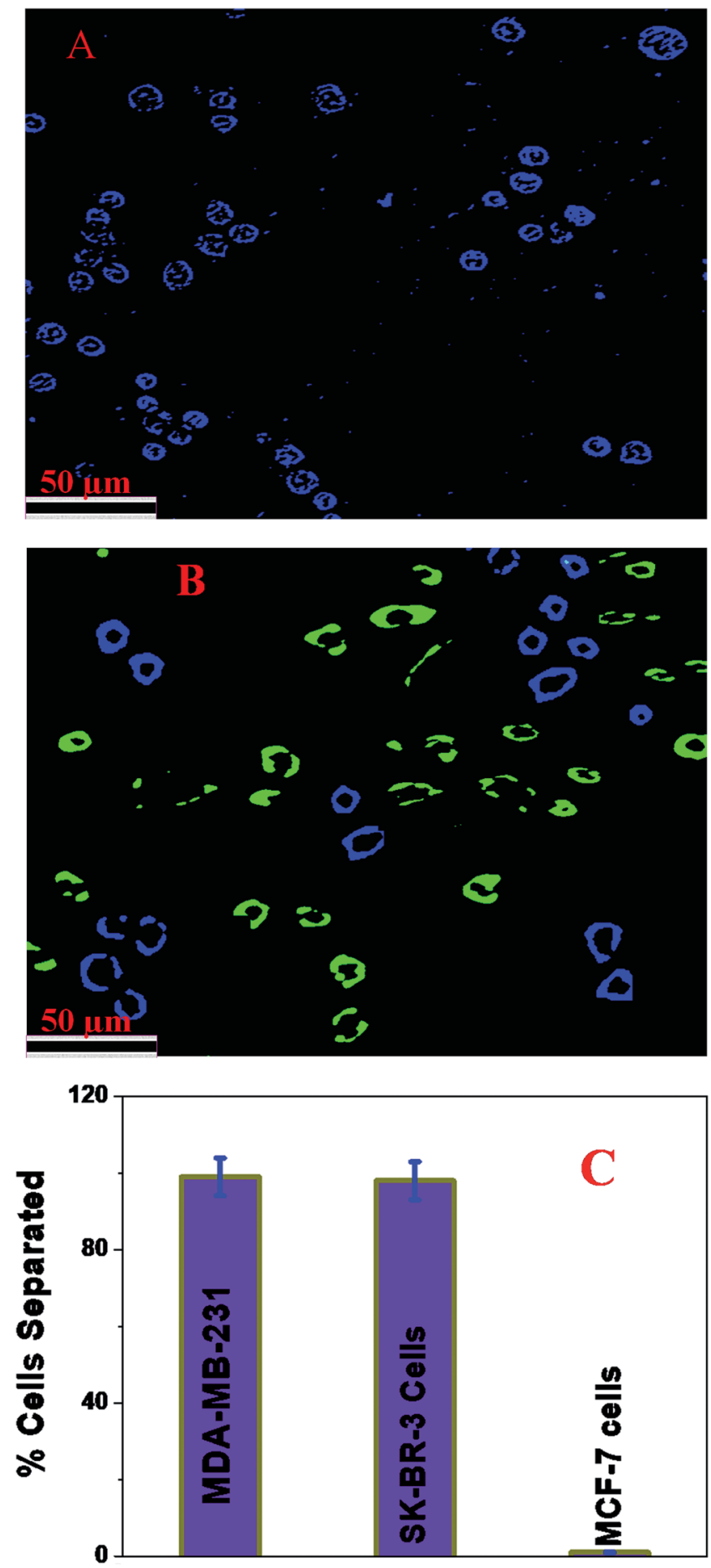

Fig. 6 (A) Single-photon luminescence image showing HER-2(+) SKBR-3 cells captured by an anti-HER-2 antibody attached to a blue fluorescent magnetic LCD-based nanosystem. (B) Multicolor fluorescence image showing that a mixture of an anti-AXL antibody attached to a green fluorescent magnetic LCD-based nanosystem and an anti-HER2 antibody attached to a blue fluorescent magnetic LCD-based nanosystem was capable of capturing MDA-MB-231 TNBC cells and HER2(+) SK-BR-3 cells simultaneously from spiked blood. (C) Percentages of HER-2(-) ER(-) MDA-MB-231 cells, HER-2(+) SK-BR-3 cells and ER(+) MCF-7 cells captured by a mixture of an anti-AXL antibody attached to a green fluorescent magnetic LCD-based nanosystem and an anti-HER2 antibody attached to a blue fluorescent magnetic LCD-based nanosystem. The error bars represent the standard deviation $(n=3)$.
Selective capture and identification of ER( + ) MCF-7 breast cancer cells from infected blood and cell mixtures using an anti-ERa antibody attached to a magnetic LCD-based nanosystem

Next, to determine whether an anti-ERa antibody attached to a magnetic LCD-based nanosystem can be used for the selective capture and identification of $\operatorname{ER}(+)$ breast cancer cells from infected blood and cell mixtures, $10^{5}$ cells per mL of HER-2(-) ER(-) MDA-MB-231 cells, $10^{5}$ cells per mL of HER-2(+) SK-BR-3 cells and $10^{5}$ cells per mL of ER(+) MCF-7 cells were incubated with $10 \mathrm{~mL}$ citrated whole rabbit blood. In the next step, we added $10^{6}$ cells per $\mathrm{mL}$ peripheral blood mononuclear cells (PBMCs) to the mixture and subjected it to gentle shaking for more than $90 \mathrm{~min}$. After that, different concentrations of an anti-ERa antibody attached to a magnetic LCD-based nanosystem were added to the infected blood sample and mixed continuously for $40 \mathrm{~min}$. After that, the targeted cells bound to the anti-ERa antibody attached to the magnetic LCD-based nanosystem were separated using a bar magnet. In the next step, the targeted cells bound to the anti-ERa antibody attached to the magnetic LCD-based nanosystem were characterized using an ELISA kit, as shown in Fig. 5. As shown in Fig. 5C, ELISA experimental data show that the capture efficiency for ER $(+)$ MCF-7 cells was greater than $98 \%$ when we used the antiERa antibody attached to a magnetic LCD-based nanosystem. On the other hand, the capture efficiency for HER-2(-) and ER(-) MDA-MB-231 and ER(-) SK-BR-3 cells was less than 3\% when we used the anti-ERa antibody attached to a magnetic LCD-based nanosystem. All the reported data clearly indicate that the anti-ERa antibody attached to a magnetic LCD-based nanosystem is highly specific for ER(+) MCF-7 cells and can be used for the targeted separation and imaging of ER(+) MCF-7 cells.

\section{Simultaneous capture and identification of MDA-MB-231} TNBC cells and HER-2(+) SK-BR-3 breast cancer cells from infected blood and cell mixtures

Next, to determine whether a mixture of an anti-HER-2 antibody attached to a blue fluorescent magnetic LCD-based nanosystem and an anti-AXL antibody attached to a green fluorescent magnetic LCD-based nanosystem can be used for the selective capture and identification of MDA-MB-231 TNBC cells and HER$2(+)$ breast cancer cells simultaneously from infected blood and cell mixtures, $10^{5}$ cells per mL of HER-2(-) ER(-) MDA-MB-231 cells, $10^{5}$ cells per mL of HER-2(+) SK-BR-3 cells and $10^{5}$ cells per $\mathrm{mL}$ of ER(+) MCF-7 cells were incubated with $10 \mathrm{~mL}$ citrated whole rabbit blood. In the next step, we added $10^{6}$ cells per $\mathrm{mL}$ peripheral blood mononuclear cells (PBMCs) to the mixture and subjected it to gentle shaking for more than $90 \mathrm{~min}$. After that, different concentrations of an anti-HER-2 antibody attached to a blue fluorescent magnetic LCD-based nanosystem and an anti-AXL antibody attached to a green fluorescent magnetic LCD-based nanosystem were added to the infected blood sample and mixed continuously for $40 \mathrm{~min}$. After that, the targeted cells bound to the anti-HER-2 antibody attached to the blue fluorescent magnetic LCD-based nanosystem and the 
targeted cells bound to the anti-AXL antibody attached to the green fluorescent magnetic LCD-based nanosystem were separated using a bar magnet. In the next step, the targeted cells bound to the anti-HER-2 antibody attached to the green fluorescent magnetic LCD-based nanosystem and the anti-AXL antibody attached to the green fluorescent magnetic LCDbased nanosystem were characterized using an ELISA kit and fluorescence mapping analysis, as shown in Fig. 6. As shown in Fig. 6C, ELISA experimental data show that the capture efficiency for HER-2(+) SK-BR-3 cells was greater than $98 \%$ and that for MDA-MB-231 TNBC cells was greater than 97\% when we used the mixture of an anti-HER-2 antibody attached to a blue fluorescent magnetic LCD-based nanosystem and an anti-AXL antibody attached to a green fluorescent magnetic LCD-based nanosystem. On the other hand, the capture efficiency for ER(+) MCF-7 cells was less than 2\%. Fig. 6B shows a multicolor blue/green single-photon luminescence image of magnetically captured cells, which indicates that HER-2(+) SK-BR-3 cells and MDA-MB-231 TNBC cells were captured simultaneously by the anti-HER-2 antibody attached to a blue fluorescent magnetic LCD-based nanosystem and the anti-AXL antibody attached to a green fluorescent magnetic LCD-based nanosystem. All the reported data clearly indicate that the anti-HER-2 antibody attached to a blue fluorescent magnetic LCD-based nanosystem and the anti-AXL antibody attached to a green fluorescent magnetic LCD-based nanosystem can be used in combination for the simultaneous separation and imaging of HER-2(+) SKBR-3 cells and MDA-MB-231 TNBC cells.

\section{Conclusion}

In conclusion, the current article reports the design of highly crystalline antibody-conjugated multifunctional multicolorluminescence nanosystems derived from the naturally available popular tropical fruits mangoes and prunes. Our design of a bioconjugated multifunctional nanoprobe exhibits excellent magnetic and multicolor fluorescence properties for the selective separation and accurate identification of TNBC and HER$2(+)$ or $\mathrm{ER} / \mathrm{PR}(+)$ breast cancer cells selectively and simultaneously. We have shown that by changing the fruits multicolor LCDs can be developed, which is mainly due to the presence of different types of surface functional group on the surface of the LCDs. We have also reported that with a change of fruits the doping of different heavy metals such as $\mathrm{Zn}, \mathrm{Mg}$, Se, $\mathrm{Cu}$, and $\mathrm{Mn}$ varies greatly between different LCDs. All the above factors introduce new energy levels for electronic transitions with comparable intensities. Reported experimental data demonstrated that the multifunctional multicolor nanosystems are capable of the selective and simultaneous capture of targeted TNBC, HER-2(+) or ER(+) breast cancer cells, and the capture efficiency can be as high as $98 \%$. We have also shown that the multicolor nanosystems are capable of mapping heterogeneous breast cancer cells simultaneously and can distinguish targeted TNBC cells from non-targeted HER-2(+) or ER/PR(+) breast cancer cells. Our findings indicate that the fruit-based green approach has excellent potential for the design of multicolor nanosystems for detecting cancer heterogeneity in clinical practice.

\section{Experimental}

All fruits were purchased from the local market. All the chemicals, including $\mathrm{H}_{3} \mathrm{PO}_{4}$, ethanol, $\mathrm{CH}_{2} \mathrm{Cl}_{2}, \mathrm{NH}_{2}$ - $\mathrm{PEG}, \mathrm{FeCl}_{3} \cdot 6 \mathrm{H}_{2} \mathrm{O}$, and 1,6-hexanedioic acid, were purchased from Fisher Scientific and Sigma-Aldrich. The human triple-negative breast cancer (TNBC) cell line MDA-MB-232, the human HER-2(+) breast cancer cell line SK-BR-3, the human $\operatorname{ER}(+)$ and $\mathrm{PR}(+)$ breast cancer cell line MCF-7 and the HaCaT normal skin cell line were purchased from the American Type Culture Collection (ATCC, Rockville, MD).

\section{Development of blue fluorescent LCDs using prunes}

Blue fluorescent LCDs were synthesized by the hydrothermal treatment of prunes using $\mathrm{H}_{3} \mathrm{PO}_{4}$. For this purpose, $0.5 \mathrm{~g}$ of dried prunes was dissolved in $5 \mathrm{~mL}$ of water and $10 \mathrm{~mL}$ of $\mathrm{H}_{3} \mathrm{PO}_{4}$. After sonication for $5 \mathrm{~min}$, the solution was added to an autoclave and heated at $180{ }^{\circ} \mathrm{C}$ for $2 \mathrm{~h}$. After that, the pH was adjusted to neutrality with $\mathrm{NaOH}$. Finally, the product was dialyzed against water for $72 \mathrm{~h}$ (molecular weight cut-off [MWCO]: $1000 \mathrm{Da}$ ) and then filtered. The blue fluorescent carbon dots were further purified by dialysis and then stored at $4{ }^{\circ} \mathrm{C}$. Yield: $0.4 \mathrm{~g}, 30 \%$.

\section{Development of green fluorescent LCDs from mangoes}

Green fluorescent LCDs were synthesized by the hydrothermal treatment of mangoes using $\mathrm{H}_{3} \mathrm{PO}_{4}$. The experimental details are described in the experimental section. In this case, we used a very similar experimental procedure to that used for prunes. For this purpose, $0.5 \mathrm{~g}$ of ripe mango was dissolved in $5 \mathrm{~mL}$ of water and $15 \mathrm{~mL}$ of $\mathrm{H}_{3} \mathrm{PO}_{4}$. After sonication for $5 \mathrm{~min}$, the solution was added to an autoclave and heated at $200{ }^{\circ} \mathrm{C}$ for $2 \mathrm{~h}$. After that, the $\mathrm{pH}$ was adjusted to neutrality with $\mathrm{NaOH}$. Finally, the product was dialyzed against water for $72 \mathrm{~h}$ (molecular weight cut-off [MWCO]: $1000 \mathrm{Da}$ ) and then filtered. The green fluorescent carbon dots were further purified by dialysis and then stored at $4{ }^{\circ} \mathrm{C}$. Yield: $0.5 \mathrm{~g}, 40 \%$.

\section{Design of carboxylic acid-conjugated $\mathrm{Fe}_{3} \mathrm{O}_{4}$ nanoparticles}

We designed carboxylic acid-functionalized $\mathrm{Fe}_{3} \mathrm{O}_{4}$ magnetic nanoparticles using a co-precipitation method from ferric chloride and 1,6-hexanedioic acid, as we reported previously, ${ }^{16-19,29}$ as shown in Scheme 1B. The experimental details have been reported previously. ${ }^{16-19,29}$ Finally, the $\mathrm{Fe}_{3} \mathrm{O}_{4}$ nanoparticles were separated from the supernatant using a magnet.

\section{Design of blue/green fluorescent magnetic LCD-based nanosystem}

For the covalent attachment of blue/green fluorescent LCDs to acid-functionalized magnetic nanoparticles, EDC-mediated esterification was used, as we reported previously. ${ }^{17,29}$ After that, the final product, namely, ester-coupled blue/green 
fluorescent LCDs attached to multifunctional magnetic nanoparticles, was separated by a magnet and washed several times with water to remove excess LCDs.

\section{Development of antibody-conjugated fluorescent LCDs attached to magnetic nanosystems}

For the selective separation and accurate identification of TNBC and HER-2(+) or ER/PR(+) breast cancer cells from blood, we have developed antibody-conjugated multifunctional multicolor-fluorescence magnetic LCD-based nanosystems. For this purpose, we developed amine-conjugated polyethylene glycol $\left(\mathrm{NH}_{2}\right.$-PEG) attached to a blue/green fluorescent magnetic LCD-based nanosystem, and then a TNBC-targeted anti-AXL antibody was attached to a green fluorescent magnetic LCD-based nanosystem by our previously reported method. ${ }^{16-19,29,46,49}$ Similarly, for the selective separation and imaging of HER-2(+) SK-BR-3 cells we have developed an antiHER-2 antibody attached to a blue fluorescent magnetic LCDbased nanosystem using the above procedure. On the other hand, for the selective separation and imaging of estrogen receptor $(\mathrm{ER})(+)$ MCF-7 cells, an anti-ERa antibody was attached to a blue fluorescent magnetic LCD-based nanosystem using the above procedure.

\section{Cell culture and incubation with antibody-conjugated blue/ green fluorescent multifunctional magnetic fruit-based LCD nanosystems}

We purchased the triple-negative breast cancer (TNBC) cell line MDA-MB-232, the human HER-2(+) breast cancer cell line SKBR-3, the human ER(+) and PR(+) breast cancer cell line MCF7 and the HaCaT normal skin cell line, which were grown according to an ATCC procedure, as we reported previously. ${ }^{16-19,29,46,49}$ Once the cell culture count was greater than $10^{6}$ cells per $\mathrm{mL}$, different concentrations of antibody-conjugated blue/green fluorescent multifunctional magnetic fruit-based LCD nanosystems were mixed with different cell lines for $30 \mathrm{~min}$. After that, unbound antibody-conjugated blue/green fluorescent multifunctional magnetic fruit-based LCD nanosystems were separated using centrifugation followed by washing with buffer three times, to make sure that antibodyconjugated blue/green fluorescent multifunctional magnetic fruit-based LCD nanosystems that were not bound to cells were separated.

\section{Multicolor luminescence imaging of captured cancer cells}

For the fluorescence imaging of antibody-conjugated blue/ green fluorescent multifunctional magnetic fruit-based LCD nanosystems attached to TNBC and HER-2(+) or ER/PR $(+)$ breast cancer cells, we used an Olympus IX71 inverted confocal fluorescence microscope fitted with a SPOT Insight digital camera, as we reported previously. ${ }^{16-19,29,46,49}$

\section{Cell viability assay}

To study the cytotoxicity of the antibody-conjugated blue/green fluorescent multifunctional magnetic fruit-based LCD nanoprobes, different concentrations of cancer and normal cells, namely, TNBC and HER-2(+) or ER/PR(+) breast cancer cells and HaCaT cells, were treated with the nanosystems at different time intervals. Finally, we measured the cell viability using an MTT (3-(4,5-dimethylthiazol-2-yl)-2,5-diphenyltetrazolium bromide) assay using a Multiskan Ascent plate reader with Ascent software (Labsystems), as we reported previously. ${ }^{16-19,29,46,49}$

\section{Conflicts of interest}

There are no conflicts to declare.

\section{Acknowledgements}

Dr Ray thanks NSF-PREM grant \# DMR-1205194, NSF CREST grant \# 1547754 and NSF RISE grant \# 1547836 for their generous funding. We are grateful for the use of the JSU Analytical Core Laboratory RCMI facility supported by NIH grant \#G12MD007581.

\section{Notes and references}

1 Breast Cancer Statistics, 2017, http://pressroom.cancer.org/ BreastCancerStats2017, accessed June 17, 2018.

2 L. A. Carey, Oncologist, 2011, 16, 71-78.

3 Y. Liu, C. Chen, P. Qian, X. Lu, B. Sun, X. Zhang, L. Wang, X. Gao, H. Li, Z. Chen, J. Tang, W. Zhang, J. Dong, R. Bai, P. E. Lobie, Q. Wu, S. Liu, H. Zhang, F. Zhao, M. S. Wicha, T. Zhu and Y. Zhao, Nat. Commun., 2015, 6, 5988.

4 W. D. Foulkes, I. E. Smith and J. S. Reis-Filho, N. Engl. J. Med., 2010, 363, 1938-1948.

5 C. Curtis, S. P. Shah, S. F. Chin, G. Turashvili, O. M. Rueda, M. J. Dunning, et al., Nature, 2012, 486, 346-352.

6 D. Zardavas, A. Irrthum, C. Swanton and M. Piccart, Nat. Rev. Clin. Oncol., 2015, 12, 381-394.

7 A. A. Alizadeh, V. Aranda, A. Bardelli, C. Blanpain, C. Bock, C. Borowski, A. Caldas, C. Califano, M. Doherty, M. Elsner, M. Esteller, R. Fitzgerald, J. O. Korbel, P. Lichter, C. E. Mason, N. Navin, D. Pe'er, K. Polyak, C. W. Roberts, L. Siu, et al., Nat. Med., 2015, 21, 846-853.

8 D. R. Welch, Cancer Res., 2016, 76, 4-6.

9 L. G. Martelotto, C. K. Ng, S. Piscuoglio, B. Weigelt and J. S. Reis-Filho, Breast Cancer Res., 2014, 16, 210.

10 S. P. Shah, A. Roth, R. Goya, A. Oloumi, G. Ha, Y. Zhao, et al., Nature, 2012, 486, 395-399.

11 L. R. Yates, M. Gerstung, S. Knappskog, C. Desmedt, G. Gundem, P. Van Loo, et al., Nat. Med., 2015, 21, 751-759.

12 L. N. Harris, N. Ismaila, L. M. Mcshane, F. Andre, D. E. Collyar and A. M. Gonzalez-Angulo, J. Clin. Oncol., 2016, 34, 1134-1150.

13 P. Zhang, Y. Cui, C. F. Anderson, C. Zhang, Y. Li, R. Wang and H. Cui, Chem. Soc. Rev., 2018, 47, 3490-3529.

14 X. L. S. Lee and J. Yoon, Chem. Soc. Rev., 2018, 47, 1174-1188. 15 S. A. Khan, A. K. Singh, D. Senapati, Z. Fan and P. C. Ray, Chem. Soc. Rev., 2012, 41, 3193-3209.

16 H. Wang, O. Chen and S. Zhou, Chem. Soc. Rev., 2018, 47, 4198-4232. 
17 A. Pramanik, A. Vangara, B. P. Viraka Nellore, S. S. Sinha, S. R. Chavva, S. Jones and P. C. Ray, ACS Appl. Mater. Interfaces, 2016, 8, 15076-15085.

18 Z. Fan, M. Shelton, A. K. Singh, D. Senapati, S. A. Khan and P. C. Ray, ACS Nano, 2012, 6, 1075-1083.

19 W. Lu, A. K. Singh, S. A. Khan, D. Senapati, H. Yu and P. C. Ray, J. Am. Chem. Soc., 2010, 132, 18103-18114.

20 H. Ding, S. B. Yu, J. S. Wei and H. M. Xiong, ACS Nano, 2016, 10, 484-491.

21 A. Cadranel, V. Strauss, J. T. Margraf, K. A. Winterfeld, C. Vogl, L. Đorđević, F. Arcudi, H. Hoelzel, N. Jux, M. Prato and D. M. Guldi, J. Am. Chem. Soc., 2018, 140, 904-907.

22 X. T. Zheng, A. Ananthanarayanan, K. Luo and P. Chen, Small, 2015, 11, 1620-1636.

23 S. Hu, A. Trinchi, P. Atkin and I. Cole, Angew. Chem., Int. Ed., 2015, 54, 2970-2974.

24 H. Ding, S. B. Yu, J. S. Wei and H. M. Xiong, ACS Nano, 2016, 10, 484-491.

25 K. Holá, M. Sudolská, S. Kalytchuk, D. Nachtigallová, A. L. Rogach, M. Otyepka and R. Zbořil, ACS Nano, 2017, 11, 12402-12410.

26 F. Ehrat, S. Bhattacharyya, J. Schneider, A. Löf, R. Wyrwich, A. L. Rogach, J. K. Stolarczyk, A. S. Urban and J. Feldmann, Nano Lett., 2017, 17, 7710-7716.

27 R. Rani, V. t. Kumar and F. Rizzolio, ACS Med. Chem. Lett., 2018, 9, 4-5.

28 Y. Chen, M. Zheng, Y. Xiao, H. Dong, H. Zhang, J. Zhuang, H. Hu, B. Lei and Y. A. Liu, Adv. Mater., 2016, 28, 312-318.

29 A. Pramanik, S. Jones, F. Pedraza, A. Vangara, C. Sweet, M. S. Williams, V. Ruppa-Kasani, S. E. Risher, D. Sardar and P. C. Ray, ACS Omega, 2017, 2, 554-562.

30 J. Zhang, Y. Yuan, G. Liang and D. H. Yu, Adv. Sci., 2015, 2, 1500002.

31 Y. Chen, H. Lian, Y. wei, X. He, Y. Chen, B. Wang, O. Zeng and J. Lin, Nanoscale, 2018, 10, 6734-6743.

32 F. Lin, C. Li, L. Dong, D. Fu and Z. Chen, Nanoscale, 2017, 9, 9056-9064.

33 Y. Zhao, Y. Zhang, X. Liu, H. Kong, Y. Wang, G. Qin, P. Cao, X. Song, X. Yan, Q. Wang and H. Qu, Sci. Rep., 2017, 4452.
34 C. J. Jeong, A. K. Roy, S. H. Kim, J.-E. Lee, J. H. Jeong, I. In and S. Y. Park, Nanoscale, 2014, 6, 15196.

35 H. Wang, Q. Chen and S. Zhou, Chem. Soc. Rev., 2018, 47, 4198-4232.

36 B. Zhi, Y. Cui, S. Wang, B. P. Frank, D. N. Williams, R. P. Brown, E. S. Melby, R. J. Hamers, Z. Rosenzweig, D. H. Fairbrother, G. Orr and C. L. Haynes, ACS Nano, 2018, 12, 5741-5752.

37 X.-W. Hua, Y.-W. Bao and F.-G. Wu., ACS Appl. Mater. Interfaces, 2018, 10, 10664-10677.

38 S. Sun, L. Zhang, K. Jiang, A. Wu and H. Lin, Chem. Mater., 2016, 28, 8659-8668.

39 C. J. Reckmeier, Y. Wang, R. Zboril and A. L. Rogach, J. Phys. Chem. C, 2016, 120, 10591-10604.

40 L. Bao, C. Liu, Z. L. Zhang and D. W. Pang, Adv. Mater., 2015, 27, 1663-1667.

41 F. Arcudi, L. Đorđević and M. Prato, Angew. Chem., Int. Ed., 2016, 128, 2147-2152.

42 X. Bai, G. Caputo, Z. D. Hao, V. T. Freitas, J. H. Zhang, R. L. Longo, O. L. Malta, R. A. S. Ferreira and N. Pinna, Nat. Commun., 2014, 5, 5702-5710.

43 F. Arcudi, L. Đorđević and M. Prato, Angew. Chem., Int. Ed., 2016, 128, 2147-2152.

44 J. Liu, N. P. Wickramaratne, S. Z. Qiao and M. Jaroniec, Nat. Mater., 2015, 14, 763-774.

45 S. Khan, N. C. Verma and C. K. Nandi, ACS Appl. Nano Mater., 2018, 1, 483-487.

46 Y. Shi, A. Pramanik, C. Tchounwou, F. Pedraza, R. A. Crouch, S. R. Chavva, A. Vangara, S. S. Sinha, S. Jones, D. Sardar, C. Hawker and P. C. Ray, ACS Appl. Mater. Interfaces, 2015, 7, 10935-10943.

47 S. Y. Lim, W. Shen and Z. Gao, Chem. Soc. Rev., 2015, 44, 362381.

48 M. Fu, F. Ehrat, Y. Wang, K. Z. Milowska, C. J. Reckmeier, A. L. Rogach, J. K. Stolarczyk, A. S. Urban and J. Feldmann, Nano Lett., 2015, 15, 6030-6035.

49 A. Pramanik, S. R. Chavva, Z. Fan, S. Sinha, B. P. Nellore and P. C. Ray, J. Phys. Chem. Lett., 2014, 5, 2150-2154.

50 https://en.wikipedia.org/wiki/Prune.

51 https://en.wikipedia.org/wiki/Mango. 